Journal of Management and Economic
Studies
$\begin{gathered}\text { 2019, 1(3): 43-61 } \\ \text { DOI: } 10.26677 / T R 1010.2019 .96 \\ \text { Journal Homepage: https://www.jomaes.org }\end{gathered}$

\title{
The Spatial Dependence of FDI and Innovative Activity in China
}

\author{
Xinzhong Li \\ Institute of Quantitative \&Technical Economics (IQTE), Chinese Academy of Social \\ Sciences (CASS), ZXLEE2000@Yahoo.com \\ Seung Rok Park \\ Enterprise Economic Institute, Korea Economic y Research Institute (KERI) \\ PSR@KERI.ORG
}

\begin{abstract}
This paper tries to develop an analyzable framework of the effects of spatial knowledge spillovers on economic growth of China. Firstly, this paper investigates spatial pattern of FDI inflows in China according to the spatial neighboring effects of knowledge flow; Secondly, this paper analyses the spatial dependence process of interaction between knowledge spillovers of FDI inflows and innovative activities in China, so as to look for insights on the mechanics of knowledge interdependences across regions;; Finally, it is expected to get the practical implications about a spatial policy of driving local area success growth. In accordance with the theory and method of spatial interdependence, heterogeneity, variation of knowledge spillovers involved with spatial econometrics, the paper uses Chinese provincial data to investigate the empirical evidences of the effects of knowledge flow and spatial spillovers on innovative activities of China. On the platform of GeoDa and EViews software system, the spatial econometrics models of spatial pattern and spillovers effects of FDI inflows are built so as to examine the spatial variation of knowledge flows in Chinese provinces. This paper points out the ideas of spatial interdependence, heterogeneity, variability of knowledge spillovers, so as to indicate spatial association process between FDI inflows and innovative activities in China. This paper constructs the methodology of Negative binomial and Poisson probability distribution model in FDI inflows and innovative activities, and applies the methods of spatial econometrics in analyzing the mechanics of dissemination and agglomeration of innovative activities in China as well as characteristics of knowledge spillovers with distance decay effect. It is expected that the studies make policymakers get a good understanding of spatial association process between FDI inflows and innovative activities in China. In addition, this paper suggests that spatial dimension of effects of knowledge spillovers generating by FDI inflows in China on innovative activities can not be ignored. The derived suggestions and policy implications of spatial agglomeration and dissemination of innovative activities are very helpful for policymakers.
\end{abstract}

Keywords: Spatial Dependence, Foreign Direct Investment, Innovative Activities, China. 


\section{Introduction}

Knowledge spillovers are one of the main sources and engines of sustainable innovation and economic growth ( Fujita and Thisse, 2002), and foreign direct investment (FDI) inflows are the main channels to promote knowledge spillovers and growth of productivity (Xinzhong Li and Tongsan Wang, 2009) ${ }^{1}$. In turn, FDI firms with advance technology or managerial knowhow knowledge, which bring the externalities of knowledge, may enhance competitive power of local firms in China. Especially, the early encouraging FDI inflows policy has been helpful for coastal regions since China launched the "open-door" policy in 1978, which makes FDI inflows located mainly in coastal developed economic regions so as to gain agglomeration economies. As a result, FDI inflows play important role in the strong growth regions in the coastal regions, and the located regions of FDI inflows are also the most intensive regions of innovation activities in China. This shows that FDI-related technological spillovers are the sources of sustainable innovation and productivity growth in coastal areas of China.

However, most of present literatures about interaction between FDI inflows and innovation activities have gone along with the traditionally theoretical framework of knowledge production function (KPF) without considering the spatial dimension since Jaffe (1989) described the local externalities in the process of creation and diffusion of knowledge by using KPF which focus on the intra-sector dimension. Although some recent studies take into account spatial and sector dimension of knowledge spillovers of FDI inflows, the magnitude or scope and spatial variation of knowledge spillovers are not examined. The rare literature fully investigates variation of knowledge spillovers with geographical distance and spatial proximity.

Just as Paul Krugman (1991) shows in a theory of new economic geography, the most striking features of the geography of economic activity are notable concentration of production in space. Especially, innovation activities have even more remarkably characteristics of spatial cluster in the geography. However, .Krugman (1991) argued that empirical measurement of knowledge spillovers would prove to be impossible because "knowledge flows are invisible, they leave no paper trail by which they may be measured and tracked" 2. That is, regarding knowledge spillovers, there are no reasons for a political boundary to stop the spilling and limit the spatial extent, such as city limit or province line, or national boundary. Thus, this has currently triggered a strand of new literature of understanding the spatial dimension of innovative activity.

Jovanovic and Nyarko (1995), and Glaeser (1999) argue that proximity makes worker with greater skills or knowledge helpfully acquire the skills and the exchange and diffusion of knowledge. Helsley(1990), Ota and Fujita (1993), Lucas (2001), Berliant, Peng, and Wang (2002), and Lucas and Rossi Hansberg (2002) show that cities evolve a transition from a mono center to a multi-center structure, and then to have a dispersion with spatial decay over distance, but, they don't take account of much detail of the knowledge spillovers and the spatial decay function. Helsley (1990) suggests that the knowledge spillovers are a byproduct of output, and in part of specific location. Thus, these papers can be considered as the first step towards a fully understanding knowledge spillovers and spatial cluster and decay of economic activity.

In fact, the knowledge spillovers generated by FDI inflows follow a complex diffusion process through geographic, social, institutional, and technological proximity (Jaffe and Trajtenberg,

$1 \mathrm{Li}$, Xinzhong, Wang, Tongsan, 2009, The Technological Spillovers Effects of FDI inflows in China, research report, Institute of Quantitative \&Technical Economics (IQTE), Chinese Academy of Social Sciences (CASS).

2 Lucas (2001), and Lucas and Rossi-Hansberg (2002) construct a spatial structure on production externalities so as to capture the externalities of knowledge. 
2002). Thus, FDI inflows-related spillovers are highly likely to have a spatial dimension. That is, FDI inflows-related spillovers present the characteristics of spatial interdependence, spatial heterogeneity, and spatial variation in the spatial dimension (Xinzhong $\mathrm{Li}$ and Tongsan Wang, 2011)3. For example, LeSage, Fisher and Scherngell (2007) attempt to incorporate spatial dimension in conjunction with KPF to demonstrate variation of spillovers with geographical distance; Blonigen and davies et al.(2007) indicate spatial autoregressive relationships of FDI inflows based on the surrounding market potential and the spatially lagged dependent variable; Baltagi, Egger and Pfaffermayr (2007) use spatial weight to investigate the determinants of FDI inflows; Coughlin and Segev (2000)examine the neighboring effects of FDI inflows based on database of Chinese provinces.

These studies show that ignoring spatial effects of FDI inflows likely causes the bias of model specification and unreliable estimation of externalities of FDI inflows. FDI inflows-related spillovers based on geographical proximity and spatial clustering can enhance productivity and competition of Chinese firms. Especially, location choice of FDI inflows and spatial clustering of innovation activities not only depend on characteristics of foreign or Chinese firms within regions, but also the factor characteristics of neighboring provinces or cities such as market size, relative factor endowments, and economic developing level and so on. Besides, spatial clustering and geographical proximity mean that knowledge flow increases the opportunities for face-to-face contacts among people working, and also implies that there exists the limited spatial process over geographical distance for knowledge spillovers.

Thus, in order to fully understand the role of spatial dimension of knowledge spillovers in enhancing the innovative capability across Chinese provinces, and explore mechanisms of interactions between FDI inflows and innovation activities, the paper tries to develop an analyzable framework of the dynamic spatial model of knowledge spillovers based on the methodology of spatial dependence, heterogeneity, variation of knowledge spillovers generated by FDI inflows in China according to database of Chinese provinces. Besides, the possible spatial effects such as geographical scope and spatial decay effects of knowledge spillovers as well as the limited spatial process of externalities generated by FDI inflows are examined. It is expected that the evidences can be found which FDI inflows enhance knowledge spillovers and technology diffusion.

The paper is organized as following. Beside the section above reviews the emerging literature on the spatial effects of FDI inflows on innovation activity and spatial empirical evidences regarding FDI inflows, the subsequent section uses probability model to examine the characteristics of spatial distribution of FDI inflows and innovation activities. The third section discusses measures of spatial dependence and empirical findings and explores externalities in the process of spatial creation and dissemination of knowledge as well as the effects of proximity on knowledge spillovers. Sections four summarize some remarks and policy implications are concluded. Finally, the acknowledgments and references are given.

\section{Spatial Distribution of FDI Inflows and Innovative Activities in China}

In accordance with the observed spatial clustering characteristics of FDI inflows and innovative activities in coastal regions of China, the conventional linear model are not appropriate to model spatial distribution of FDI inflows and innovative activities. Therefore, Negative binomial (NB) and Poisson probability distribution models are more appropriate approaches to be superior to others for describing the characteristics of count data with cluster. Thereby, NB and Poisson model can be used to approximately simulate the spatial agglomeration of FDI

3 Li, Xinzhong, Wang, Tongsan, 2011, The Effects of FDI inflows on Chinese sustainable innovation, research report, Institute of Quantitative \&Technical Economics (IQTE), Chinese Academy of Social Sciences (CASS). 
inflows and innovative performance so as to understand the mechanisms of dissemination and agglomeration of innovative activities as well as the effects of technological and geographical proximities on FDI inflows and innovative activities.

\section{Probability Model of Spatial Distribution of FDI Inflows and Innovative Activities}

In theory, when $\sigma^{2}(X)>E(X)$, NB distribution model may be simulated the variable $X$ which has the characteristics of clusters; when $\sigma^{2}(X)=E(X)$, Poisson distribution model may be simulated the variable $X$ which has the characteristics of clusters; when $\sigma^{2}(X)<E(X)$, Binomial distribution model may be simulated the variable $X$. In addition, NB distribution can be combined by a few Poisson distribution with the different expectations of the variable $X$, and the limiting distribution of NB distribution is regard as Poisson distribution.

In particular, zero-inflation probability may be present when there are frequently so low probabilities over some time period and in regions. That is, sometimes the conventional applications of NB and Poisson models don't properly address the possibility of zero-inflated counting processes. As a consequence, zero-inflated probability processes are considered as an extension of standard Poisson and negative binomial regression, such as the zero-inflated Poisson (ZIP) and zero-inflated negative binomial (ZINB) regression models have widely applied in practical frequency analysis (Shankar and Milton et al. 1997), which may generate the better results of frequency simulation.

Thus, in order to illustrate the spatial distribution characteristics of FDI inflows and innovative activities, statistical analysis is started with Poisson model in frequency analysis. When the observed data obeys $\sigma^{2}(X)=E(X)$, the Poisson mode is as following:

$$
\begin{aligned}
& P\left(x_{i j}\right)=\exp \left(-\lambda_{i j}\right) \lambda_{i j}^{x_{i j}} / x_{i j} ! \\
& E\left(x_{i j}\right)=\exp \left(\beta Z_{i j}\right)
\end{aligned}
$$

Where $P\left(x_{i j}\right)$ is the probability of spatial distribution of the variable $X$ in region $i$ and time period $j ; x_{i j}$ is the grade; $\lambda_{i j}$ is the expected value of the variable $x_{i j}$, that is, $E\left(x_{i j}\right)=\lambda_{i j} ; Z_{i j}$ describes the vector of grade characteristics affecting the frequency of FDI inflows and innovative; $\beta$ is the vector of regression coefficients to be estimated by standard maximum likelihood methods.

However, when the observed data presents the characteristics of over-dispersion, that is, it is subject to $\sigma^{2}(X)>E(X)$, Poisson model may result in biased estimation of model. Thus, NB model is applied in simulation of spatial distribution. The modified equation is derived as following:

$$
\begin{gathered}
\lambda_{i j}=\exp \left(\beta Z_{i j}+\varepsilon_{i j}\right) \\
\sigma^{2}\left(x_{i j}\right)=E\left(x_{i j}\right)+\alpha E\left(x_{i j}\right)^{2}
\end{gathered}
$$

Where $\exp \left(\varepsilon_{i j}\right)$ is a $\varepsilon_{i j}$ error term that following Gamma distribution, in order to allow variance ( $\left.\sigma^{2}\left(x_{i j}\right)\right)$ may be unequal to the mean $E\left(x_{i j}\right)$, which is very different from requirement of the Poisson model; $\alpha$ is a adjustable parameter between Poisson and NB model. When parameter $\alpha$ approaches zero, Poisson model is selected, otherwise, NB model should be considered. Thus, NB model can be formed as following: 


$$
P\left(x_{i j}\right)=\frac{\Gamma\left((1 / \alpha)+x_{i j}\right)}{\Gamma(1 / \alpha) x_{i j} !}\left(\frac{1 / \alpha}{(1 / \alpha)+\lambda_{i j}}\right)^{1 / \alpha}\left(\frac{\lambda_{i j}}{(1 / \alpha)+\lambda_{i j}}\right)^{x_{i j}}
$$

Where $P\left(x_{i j}\right)$ can be estimated by moments and standard maximum likelihood methods, which can be simplified as such the forms as $P\left(x_{i j}\right)=\left(\hat{\kappa}+x_{i j}-1\right) R\left(\hat{\kappa}, x_{i j}\right) P\left(x_{i j}-1\right) / x_{i j}$, $R\left(\hat{\kappa}, x_{i j}\right)=E\left(x_{i j}\right) /\left(\hat{\kappa}+E\left(x_{i j}\right)\right), \hat{\kappa}=E\left(x_{i j}\right) /\left(\sigma^{2}\left(x_{i j}\right)-E\left(x_{i j}\right)\right)$.

\section{Test Statistic of Spatial Distribution}

The test of spatial distribution models are started with goodness-of-fit test of $\chi^{2}$ distribution. That is, in accordance with the observed data of FDI inflows and innovative activities, the NB and Poisson model are tested respectively based on the data set of Chinese provinces and cities level. The formula for the test is as following:

$$
\chi^{2}=\left(\sum_{i=1}^{n} x_{i j}^{2} f_{i j}-\left(\sum_{i=1}^{n} x_{i j} f_{i j}\right)^{2} / \sum_{i=1}^{n} f_{i j}\right) / \sum_{i=1}^{n} f_{i j}
$$

Where $f_{i j}$ is the observed frequency of variable $X$ in region $i$ and time period $j$. The test values of $\chi^{2}$ distribution and test results of probability distribution model see table 1 , table 2 , and table 3 . The test results of probability distribution model show that FDI inflows, which include number of manufacture firm, R\&D firm, managing \& marketing firm, and total sectors, as well as innovative activities, which include number of patent applications examined such as inventions, utility models, designs, are subject to the NB probability distribution, which is also consistent with the observation of FDI firms and innovative activities concentrated in coastal cities and provinces.

However, because probability of FDI firm distribution frequently presents so low value to approach zero in regions, ZIP or ZINB model may be developed in the observed count data of FDI firms and innovative activities, and assume that the events $Y$ are independent. Because the NB model is favored for the observed data, rather than Poisson model, the ZINB models of the modified probabilities are only considered and are formed as following:

$$
\begin{aligned}
& \operatorname{Prob}\left(Y_{i j}=0\right)=p_{0}+\left(1-p_{0}\right)\left(\frac{1 / \alpha}{(1 / \alpha)+\lambda_{i j}}\right)^{1 / \alpha} \\
& \operatorname{Prob}\left(Y_{i j}=c_{i}\right)=\left(1-p_{0}\right) \frac{\Gamma\left((1 / \alpha)+c_{i}\right)}{\Gamma(1 / \alpha) c_{i} !}\left(\frac{1 / \alpha}{(1 / \alpha)+\lambda_{i j}}\right)^{1 / \alpha}\left(\frac{\lambda_{i j}}{(1 / \alpha)+\lambda_{i j}}\right)^{c_{j}}
\end{aligned}
$$

Where $c_{i}=1,2,3 \ldots \ldots n$ is the grade number of events such as FDI firms and patent applications examined; $p_{0}$ is subject to the formulas as following:

$$
\begin{aligned}
& E\left(y_{i j}\right)=\left(1-p_{0}\right) \lambda_{i j} \\
& \sigma^{2}\left(y_{i j}\right)=\left(1-p_{0}\right) \lambda_{i j}\left(1+\left(p_{0}+\alpha\right) \lambda_{i j}\right) \\
& \frac{\sigma^{2}\left(y_{i j}\right)}{E\left(y_{i j}\right)}=1+\left(\frac{p_{0}+\alpha}{1-p_{0}}\right) * E\left(y_{i j}\right)
\end{aligned}
$$

Obviously, the variance is greater than the mean in ZINB model, which shows that observed data has the characteristics of clusters in ZINB model. But, because Poisson and ZIP or NB and ZINB counterparts are not nested, this test can't be conducted directly. Thus, the statistical test is critical for the selecting, ZIP, ZINB or not. According to the methodology for non-nested models developed by Vuong and Quang (1989), let random variable $Y=y_{i}$, and assume that the 
probability density functions of ZINB and NB model are respectively the $f_{1}\left(y_{i} / x_{i}\right)$ and $f_{2}\left(y_{i} / x_{i}\right)$. As a result, the test statistic for non-nested ZINB and NB or ZIP and Poisson is as following:

$$
\begin{gathered}
\eta_{i}=\operatorname{Ln}\left(\frac{f_{1}\left(y_{i} / x_{i}\right)}{f_{2}\left(y_{i} / x_{i}\right)}\right) \\
\omega=\frac{\sqrt{n}\left(\sum_{i=1}^{n} \eta_{i} / n\right)}{\sqrt{\sum_{i=1}^{n}\left(\eta_{i}-\bar{\eta}\right)^{2} / n}}
\end{gathered}
$$

Where, $\eta_{i}$ is the logarithm of ration of NB to ZINB probability ; $\bar{\eta}$ is the mean of $\eta_{i} ; n$ is the sample size. Vuong's value obeys an asymptotical standard normally distribution, and if $|\omega|$ is less than 1.96, which is the $95 \%$ confidence level for the t-test. Thus, if the $\omega$ value is greater than 1.96, the observed data obeys the ZINB or ZIP model, while if the $\omega$ is less than 1.96, the observed data obey NB or Poisson model.

\section{Empirical Results of Spatial Distribution}

The statistical results based on Vuong's tests see table 1., table 2, and table 3. Based on the provincial count data of such as manufacture firm, R\&D firm, managing \& marketing firm, and total sectors, as well as number of patent applications examined such as inventions, utility models, and designs, the results show that the $\omega$ values are less than 1.96. Thus, the observed count data obeys the NB probability distribution, rather than ZINB model, which are also consistent with the observation of FDI firms and innovative activities concentrated in coastal cities and provinces. But, based on the data of cities in China, only manufacture and managing \& marketing firm obey NB model, and R\&D firm and total sectors obey neither NB model nor ZINB model.

\begin{tabular}{|c|c|c|c|c|}
\hline Parameter & Manufacture firm & R\&D firm & Managing \& marketing & Total sectors \\
\hline$E(X)$ & 2.6356 & 1.1989 & 1.6453 & 2.2952 \\
\hline$\sigma^{2}(X)$ & 14.5324 & 3.7945 & 4.3191 & 12.2134 \\
\hline$\hat{\kappa}$ (moments) & 0.5839 & 0.5537 & 1.0124 & 0.5312 \\
\hline$\hat{\kappa}$ (likelihood) & 0.6755 & 0.9377 & 0.9440 & 0.6590 \\
\hline$R$ & 0.7960 & 0.5611 & 0.6354 & 0.7769 \\
\hline$\chi^{2}($ poisson $)$ & $9.18 \mathrm{E}+12$ & $1.14 \mathrm{E}+06$ & 1040.4945 & $1.38 \mathrm{E}+14$ \\
\hline$\chi^{2}(N B)$ & 28.2064 & 45.1926 & 5.7283 & 45.7072 \\
\hline \multirow[t]{5}{*}{ Vuong value } & -8.7480 & -8.3222 & -7.8351 & -9.0488 \\
\hline & $\chi^{2}($ poisson $)>$ & $\chi^{2}($ poisson $)>$ & $\chi^{2}($ poisson $)>$ & $\chi^{2}($ poisson $)>$ \\
\hline & $\chi^{2}(29,0.001)=58.301$ & $\chi^{2}(29,0.001)=58.301$ & $\chi^{2}(29,0.001)=58.301$ & $>\chi^{2}(29,0.001)=58.301$ \\
\hline & Rejecting hypothesis & Rejecting hypothesi & Rejecting hypothesis & Rejecting hypothesis \\
\hline & $\chi^{2}(N B, 28)<$ & $\chi^{2}(N B, 28)<$ & $\chi^{2}(N B, 28)<$ & $\chi^{2}(N B, 28)<$ \\
\hline \multirow[t]{5}{*}{ Test } & $\chi^{2}(0.1)=37.9160$ & $\chi^{2}(0.01)=48.2782$ & $\chi^{2}(0.1)=37.9160$ & $\chi^{2}(0.01)=48.2782$ \\
\hline & Accepting hypothesis & Accepting hypothesis & Accepting hypothesis & Accepting hypothesis \\
\hline & Obey NB distribution & Obey NB distribution & Obey NB distribution & Obey NB distribution \\
\hline & $\begin{array}{l}V_{\text {TrID }}<\text { Vuong }(0.95) \\
=1.96\end{array}$ & $\begin{array}{l}V_{\text {TIND }}<\operatorname{Vuong}(0.95) \\
=1.96\end{array}$ & $\begin{array}{l}V_{\text {ZINB }}<\text { Vuong }(0.95) \\
=1.96\end{array}$ & $\begin{array}{l}V_{Z I N B}<\operatorname{Vuong}(0.95) \\
=1.96\end{array}$ \\
\hline & Obey NB distribution & Obey NB distribution & Obey NB distribution & Obey NB distribution \\
\hline
\end{tabular}

Table 1. Probability Model and Test of Spatial Distribution of FDI Firms in Chinese Provinces

Note: the data come from ministry of business and other China statistical yearbooks, and are required the number of multinational corporations above 10 million dollar of designated size by year total sales income. 
Journal of Management and Economic Studies, vol.1, issue.3, pp.43-61

Table 2. Probability Model and Test of Spatial Distribution of Innovative Output in Chinese Provinces

\begin{tabular}{|c|c|c|c|c|}
\hline Parameter & total patents & inventions & utility models & designs \\
\hline$E(X)$ & 5.2960 & 5.4202 & 6.2886 & 4.0478 \\
\hline$\sigma^{2}(X)$ & 35.7037 & 36.8668 & 40.9518 & 27.2448 \\
\hline$\hat{\kappa}$ (moments) & 0.9224 & 0.9343 & 1.1409 & 0.7063 \\
\hline$\hat{\kappa}$ (likelihood) & 0.8011 & 0.8276 & 0.9313 & 0.7118 \\
\hline$R$ & 0.8686 & 0.8675 & 0.8710 & 0.8505 \\
\hline$\chi^{2}($ poisson $)$ & $6.33 \mathrm{E}+08$ & $1.59 \mathrm{E}+08$ & $2.74 \mathrm{E}+07$ & $9.62 \mathrm{E}+09$ \\
\hline$\chi^{2}(N B)$ & 10202.0325 & 2015.2017 & 4113.3921 & 7604.8419 \\
\hline Vuong value & -6.9964 & -6.8029 & -6.0338 & -7.9366 \\
\hline \multirow{9}{*}{ Test } & $\chi^{2}($ poisson $)>$ & $\chi^{2}($ poisson $)>$ & $\chi^{2}($ poisson $)>$ & $\chi^{2}($ poisson $)>$ \\
\hline & $\chi^{2}(29,0.001)=58.301$ & $\chi^{2}(29,0.001)=58.301$ & $\chi^{2}(29,0.001)=58.301$ & $>\chi^{2}(29,0.001)=58.301$ \\
\hline & Rejecting & hypothesis Rejecting hypothesis & Rejecting hypothesis & Rejecting hypothesis \\
\hline & $\chi^{2}(N B, 28)>$ & $\chi^{2}(N B, 28)>$ & $\chi^{2}(N B, 28)>$ & $\chi^{2}(N B, 28)>$ \\
\hline & $\chi^{2}(0.001)=56.893$ & $\chi^{2}(0.001)=56.893$ & $\chi^{2}(0.001)=56.893$ & $\chi^{2}(0.001)=56.893$ \\
\hline & Rejecting hypothesi & isRejecting hypothesis & Rejecting & hypothesis \\
\hline & $V_{Z I N B}<\operatorname{Vuong}(0.95)$ & $V_{Z I N B}<\operatorname{Vuong}(0.95)$ & $V_{\text {ZINB }}<\operatorname{Vuong}(0.95)$ & $V_{Z I N B}<\operatorname{Vuong}(0.95)$ \\
\hline & $=1.96$ & $=1.96$ & $=1.96$ & $=1.96$ \\
\hline & Obey NB distribution & Obey NB distribution & Obey NB distribution & Obey NB distribution \\
\hline
\end{tabular}

Note: the data come from ministry of business and other China statistical yearbooks, and are required the number of multinational corporations above 10 million dollar of designated size by year total sales income.

Table 3. Probability Model and Test of Spatial Distribution of FDI Firms in Chinese Cities

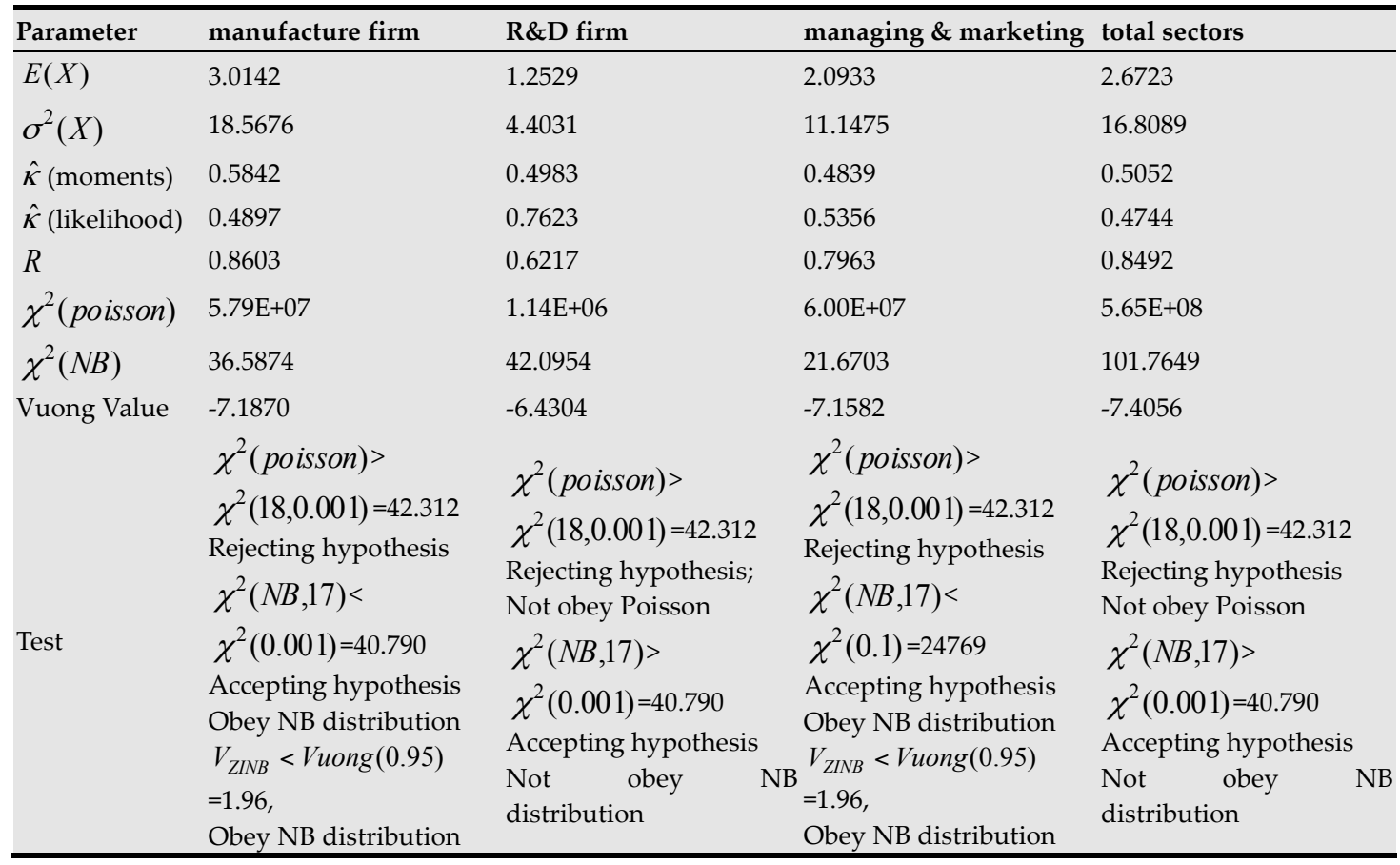

Note: the data come from ministry of business and other China statistical yearbooks, and are required the number of multinational corporations above 10 million dollar of designated size by year total sales income.

These results mean that there still exist the greater potentials for further introducing FDI inflows and sustainable innovation in China. Besides, the evidences of spatial agglomeration are helpful for further investigating the location determinants affecting innovative activities and different branches of FDI firms in global value chains. On the other hand, it is also suggested 
that, in accordance with the characteristics of spatial agglomeration of FDI firms in global value chains, maker of decision should preferentially support innovative activities in the advantageous location so as to boost agglomeration economies and spatial spillovers of FDI inflows.

\section{Measures of Spatial Dependence}

Just as is described by Tobler's first law of geography, spatial dependence means that everything is related to everything else over space, but near things are more related than distant things. Thus, spatial dependence between FDI inflows and innovative activities implies the existence of spatial process. Spatial dependence can be positive or negative, and positive spatial dependence much more common than negative. Positive spatial dependence occurs when similar values cluster one another over space. Negative spatial dependence occurs when dissimilar values occur near one another over space.

\section{Statistic of Spatial Dependence}

Measures of spatial dependence include global and local spatial dependence based on Moran's Index (Moran 1950). Global measures indicate the same pattern or process over the entire geographic area, which are expressed by an average for the entire area. Local measures indicate different patterns or processes over different parts of the region, which have a unique number for each location. Thus, the formulas for global and local spatial dependence are described respectively as following:

$$
\begin{gathered}
\text { Moran's } I=\frac{N \sum_{i=1}^{N} \sum_{j=1}^{N} w_{i j}\left(x_{i}-\bar{x}\right)\left(x_{j}-\bar{x}\right)}{\sum_{i=1}^{N}\left(x_{i}-\bar{x}\right)^{2} \sum_{i=1}^{N} \sum_{j=1}^{N} w_{i j}} \\
Z(I)=\frac{\text { Moran's } I-E(I)}{\sigma_{I}}
\end{gathered}
$$

Where Moran's $I$ is the calculated value for global spatial dependence; $N$ is the number of observations such as points or polygons; $w_{i j}$ is a weight indexing location $i$ relative to the contiguous location $j ; x_{i}$ is the variable value at a particular location $i ; \bar{x}$ is the mean of the variable $x_{i} ; Z(I)$ is the standard deviation for standard normal distribution for test of statistical significance of spatial dependence; $E(I)$ is the expected value; $\sigma_{I}$ is the standard deviation for as asymptotical normal distribution.

$$
\begin{gathered}
I_{i}=z_{i} \sum_{j=1}^{N} w_{i j} z_{j} \\
Z\left(I_{i}\right)=\frac{I_{i}-E\left(I_{i}\right)}{\sigma\left(I_{i}\right)}
\end{gathered}
$$

Where $I_{i}$ is the calculated value for local spatial dependence; $z_{i}, z_{j}$ are respectively the standard values of the original variables $x_{i}$ and $x_{j} ; E\left(I_{i}\right)$ is the expected value of $I_{i} ; \sigma\left(I_{i}\right)$ is the standard deviation of $I_{i} ; Z\left(I_{i}\right)$ is the standard deviation for standard normal distribution for test of statistical significance of spatial dependence. 


\section{Empirical Analysis of the Spatial Effects of FDI Inflows on Spatial Distribution of Innovative Activities in China}

The derived results based on calculation of Moran index indicate the existence of strong positive spatial dependence process. That is, there are the strong patent application activities in coastal cities and provinces, which are consistent with empirical observation on FDI inflows and innovative activities clustering in coastal regions. Besides, because of existence of spatial dependence, innovative activities have also close associated with FDI inflows in contiguous regions, and the spatial effects have a highly statistical significance in the global Moran index. Thus, the spatial spillovers generated by FDI inflows have the significant influence on growth of number of patent applications examined such as inventions, utility models, designs in China.

Table 4., Table 5., Table 6., Table 7. show the significant effects of FDI inflow on spatial distribution of innovative activities in the spatial dimension. According to the evolution of innovative activities from 1999 to 2012, as a whole, the innovative activities have been spreading to middle-western regions from coastal regions, and intensity of the innovative activities have greatly increased over year although it is very different for spatial spillovers effects of FDI inflows on spatial distribution of the different type of innovative activities such as inventions, utility models, designs, and total patent applications.

Table 4. Global Spatial Dependence and Test of Patent Applications of Inventions based on Contiguity of FDI Inflows

\begin{tabular}{|c|c|c|c|c|c|}
\hline Year & Moran's I & $\mathrm{E}(\mathrm{I})$ & Mean & Sd & P-value \\
\hline 1999 & 0.0771 & -0.0357 & -0.0048 & 0.0967 & 0.4590 \\
\hline 2000 & 0.1480 & -0.0357 & -0.0038 & 0.0992 & 0.1110 \\
\hline 2001 & 0.1059 & -0.0357 & -0.0077 & 0.0973 & 0.2910 \\
\hline 2002 & 0.1285 & -0.0357 & -0.0107 & 0.1026 & 0.2140 \\
\hline 2003 & 0.1965 & -0.0357 & -0.0072 & 0.1029 & 0.0620 \\
\hline 2004 & 0.2076 & -0.0357 & -0.0085 & 0.1042 & 0.0520 \\
\hline 2005 & 0.2555 & -0.0357 & -0.0126 & 0.1057 & 0.0200 \\
\hline 2006 & 0.2625 & -0.0357 & -0.0152 & 0.0963 & 0.0160 \\
\hline 2007 & 0.2683 & -0.0357 & -0.0091 & 0.1086 & 0.0250 \\
\hline 2008 & 0.2022 & -0.0357 & -0.0152 & 0.1091 & 0.0510 \\
\hline 2009 & 0.2421 & -0.0357 & -0.0197 & 0.1061 & 0.0280 \\
\hline 2010 & 0.2649 & -0.0357 & -0.0194 & 0.1106 & 0.0210 \\
\hline 2011 & 0.2592 & -0.0357 & -0.0234 & 0.1137 & 0.0220 \\
\hline 2012 & 0.2680 & -0.0357 & -0.0185 & 0.1093 & 0.0260 \\
\hline
\end{tabular}

Note: Multivariate Moran's I of both patent applications of inventions and FDI inflows is measured by the Queen Contiguity Weight.

Table 5. Global Spatial Dependence and Test of Patent Applications of Utility Models based on Contiguity of FDI Inflows 
Journal of Management and Economic Studies, vol.1, issue.3, pp.43-61

\begin{tabular}{ccccccc}
\hline Year & Moran's $I$ & E(I) & \multicolumn{2}{c}{ Mean } & \multicolumn{2}{c}{ P-value } \\
\hline 1999 & 0.0895 & -0.0357 & -0.0078 & 0.0991 & 0.4060 \\
2000 & 0.0761 & -0.0357 & -0.0036 & 0.1124 & 0.5270 \\
2001 & 0.1356 & -0.0357 & -0.0143 & 0.1061 & 0.2020 \\
2002 & 0.1864 & -0.0357 & -0.0077 & 0.1041 & 0.0750 \\
2003 & 0.2611 & -0.0357 & -0.0160 & 0.1078 & 0.0210 \\
2004 & 0.2842 & -0.0357 & -0.0210 & 0.1038 & 0.0090 \\
2005 & 0.3193 & -0.0357 & -0.0123 & 0.1139 & 0.0090 \\
2006 & 0.3441 & -0.0357 & -0.0183 & 0.1139 & 0.0060 \\
2007 & 0.3741 & -0.0357 & -0.0174 & 0.1140 & 0.0060 \\
2008 & 0.3511 & -0.0357 & -0.0183 & 0.1234 & 0.0090 \\
2009 & 0.3717 & -0.0357 & -0.0255 & 0.1171 & 0.0010 \\
2010 & 0.3892 & -0.0357 & -0.0233 & 0.1140 & 0.0010 \\
2011 & 0.3847 & -0.0357 & -0.0289 & 0.1162 & 0.0030 \\
2012 & 0.3795 & -0.0357 & -0.0169 & 0.1188 & 0.0070 \\
\hline
\end{tabular}

Note: Multivariate Moran's I of both patent applications of inventions and FDI inflows is measured by the Queen Contiguity Weight.

Table 6. Global Spatial Dependence and Test of Patent Applications of Designs based on Contiguity of FDI Inflows

\begin{tabular}{ccccccc}
\hline Year & Moran's $I$ & E(I) & \multicolumn{2}{c}{ Mean } & \multicolumn{2}{c}{ P-value } \\
\hline 1999 & 0.2212 & -0.0357 & -0.0224 & 0.1020 & 0.0340 \\
2000 & 0.2428 & -0.0357 & -0.0226 & 0.0985 & 0.0160 \\
2001 & 0.2771 & -0.0357 & -0.0256 & 0.1050 & 0.0200 \\
2002 & 0.3731 & -0.0357 & -0.0143 & 0.1109 & 0.0090 \\
2003 & 0.4644 & -0.0357 & -0.0164 & 0.1104 & 0.0040 \\
2004 & 0.4045 & -0.0357 & -0.0265 & 0.1069 & 0.0010 \\
2005 & 0.4361 & -0.0357 & -0.0259 & 0.1146 & 0.0010 \\
2006 & 0.4313 & -0.0357 & -0.0298 & 0.1167 & 0.0030 \\
2007 & 0.4475 & -0.0357 & -0.0237 & 0.1221 & 0.0060 \\
2008 & 0.4130 & -0.0357 & -0.0279 & 0.1204 & 0.0020 \\
2009 & 0.3856 & -0.0357 & -0.0353 & 0.1128 & 0.0030 \\
2010 & 0.3773 & -0.0357 & -0.0319 & 0.1131 & 0.0080 \\
2011 & 0.3137 & -0.0357 & -0.0328 & 0.1058 & 0.0070 \\
2012 & 0.2573 & -0.0357 & -0.0281 & 0.0989 & 0.0110 \\
\hline
\end{tabular}

Note: Multivariate Moran's I of both patent applications of designs and FDI inflows is measured by the Queen Contiguity Weight.

Table 7. Global Spatial Dependence and Test of Total Patent Applications based on Contiguity of FDI Inflows 


\begin{tabular}{llllll}
\hline Year & Moran's $I$ & E(I) & Mean & Sd & P-value \\
\hline 1999 & 0.1409 & -0.0357 & -0.0156 & 0.1040 & 0.1610 \\
2000 & 0.1610 & -0.0357 & -0.0087 & 0.1090 & 0.1350 \\
2001 & 0.1919 & -0.0357 & -0.0187 & 0.1031 & 0.0550 \\
2002 & 0.2770 & -0.0357 & -0.0163 & 0.1039 & 0.0140 \\
2003 & 0.3423 & -0.0357 & -0.0140 & 0.1092 & 0.0080 \\
2004 & 0.3147 & -0.0357 & -0.0222 & 0.1086 & 0.0060 \\
2005 & 0.3645 & -0.0357 & -0.0174 & 0.1108 & 0.0030 \\
2006 & 0.3702 & -0.0357 & -0.0252 & 0.1086 & 0.0020 \\
2007 & 0.3978 & -0.0357 & -0.0100 & 0.1153 & 0.0020 \\
2008 & 0.3607 & -0.0357 & -0.0237 & 0.1204 & 0.0070 \\
2009 & 0.3711 & -0.0357 & -0.0203 & 0.1110 & 0.0060 \\
2010 & 0.3838 & -0.0357 & -0.0234 & 0.1265 & 0.0080 \\
2011 & 0.3591 & -0.0357 & -0.0262 & 0.1181 & 0.0050 \\
2012 & 0.3520 & -0.0357 & -0.0262 & 0.1175 & 0.0090 \\
\hline
\end{tabular}

Note: Multivariate Moran's I of both total patent applications and FDI inflows is measured by the Queen Contiguity Weight.

For example, based on calculation of global Moran's $I$, global spatial dependence between FDI inflows and innovative activities such as inventions, utility models, designs, and total patent applications are respectively examined. The spatial effects of FDI inflows on designs have always held the higher values in comparison with inventions, total patent applications, and utility models, Statistical values of Moran's $I$ on the designs have increased considerably from 0.2212 in 1999 to 0.4475 in 2007 and decreased from 0.4475 in 2007 to 0.2573 in 2012, which have the trend from agglomeration to diffusion over time with highly statistical significance. However, spatial effects of FDI inflows on inventions have always maintained the lower values in comparison with utility models, total patent applications and designs, even so, the values of Moran's I on inventions have still increased from 0.0771 in 1999 to 0.2680 in 2012, which have been the trend from agglomeration and have begun to be the statistical significance in 2003 . Nevertheless, spatial effects of FDI inflows on utility models and total patent applications have always ranged between inventions and designs. In particular, the values of Moran's I on utility models have increased from 0.0895 in 1999 to 0.3795 in 2012, which have been the strong trend of agglomeration over time and have begun to be the statistical significance in 2002. Similarly, the values of Moran's $I$ on total patent applications have increased from 0.1409 in 1999 to 0.3520 in 2012, which also have been the strong trend of agglomeration over time and have begun to be the statistical significance in 2001.

Table 8., Table 9. respectively show the decay effects of global spatial dependence over time along with increasing orders of contiguity for total patent applications examined and FDI inflows in China. For example, with the increasing of the number of order of contiguity, in 1999, Moran index of total patent applications gradually decreases from 0.0852 at $4^{\text {th }}$-order to -0.0218 at $24^{\text {th }}$-order, and in 2012, Moran index of total patent applications gradually decreases from 0.2836 at $4^{\text {th }}$-order to -0.0233 at $24^{\text {th }}-$ order. Similarly, in 1999 , Moran index of FDI inflows gradually decreases from 0.0849 at $4^{\text {th }}$-order to -0.0302 at $24^{\text {th }}$-order, and in 2012, Moran index of FDI inflows gradually decreases from 0.2503 at $4^{\text {th }}$-order to -0.0212 at $24^{\text {th }}$-order. Thus, the derived results means that the spatial process of externalities generated by FDI inflows is limited and variable, that is, the scope and the extent of spatial spillovers effects generated by FDI inflows on innovative activities vary with distance, which indicates the characteristics with spatial interdependence, heterogeneity, variation of spatial effects

Table 8. The Decay Effects of Global Spatial Dependence and Test of Total Patent Applications in Chinese Province. 
Journal of Management and Economic Studies, vol.1, issue.3, pp.43-61

\begin{tabular}{lllllllll}
\hline Year & $\begin{array}{l}\mathbf{4}^{\text {th }} \mathbf{~} \\
\text { order }\end{array}$ & $\begin{array}{l}\mathbf{6}^{\text {th }} \\
\text { order }\end{array}$ & $\mathbf{8}^{\text {th }}$-order & $\mathbf{1 0}^{\text {th }}$-order & $\mathbf{1 2}^{\text {h}}$-order & $\mathbf{1 6}^{\text {th }}$-order & $\mathbf{2 0}^{\text {th }}$-order & $\mathbf{2 4}^{\text {h}}$-order \\
\hline 1999 & 0.0852 & 0.0639 & 0.0598 & 0.0431 & 0.0351 & 0.0453 & 0.0095 & -0.0218 \\
2000 & 0.0449 & 0.0315 & 0.0364 & 0.0215 & 0.0326 & 0.0455 & 0.0094 & -0.0222 \\
2001 & 0.0384 & 0.0236 & 0.0286 & 0.0147 & 0.0317 & 0.0444 & 0.0072 & -0.0218 \\
2002 & 0.0533 & 0.0343 & 0.0437 & 0.0325 & 0.0397 & 0.0526 & 0.0128 & -0.0199 \\
2003 & 0.0687 & 0.0420 & 0.0528 & 0.0429 & 0.0486 & 0.0600 & 0.0170 & -0.0182 \\
2004 & 0.0942 & 0.0555 & 0.0700 & 0.0590 & 0.0528 & 0.0664 & 0.0196 & -0.0179 \\
2005 & 0.1064 & 0.0529 & 0.0737 & 0.0632 & 0.0517 & 0.0705 & 0.0195 & -0.0197 \\
2006 & 0.1348 & 0.0649 & 0.0873 & 0.0738 & 0.0563 & 0.0775 & 0.0220 & -0.0193 \\
2007 & 0.1732 & 0.0862 & 0.1078 & 0.0872 & 0.0618 & 0.0826 & 0.0230 & -0.0192 \\
2008 & 0.2111 & 0.1056 & 0.1262 & 0.0987 & 0.0668 & 0.0880 & 0.0234 & -0.0203 \\
2009 & 0.2312 & 0.1161 & 0.1285 & 0.0986 & 0.0726 & 0.0878 & 0.0226 & -0.0198 \\
2010 & 0.2796 & 0.1406 & 0.1516 & 0.1217 & 0.0855 & 0.0966 & 0.0255 & -0.0195 \\
2011 & 0.2627 & 0.1297 & 0.1487 & 0.1187 & 0.0836 & 0.0906 & 0.0234 & -0.0206 \\
2012 & 0.2836 & 0.1424 & 0.1440 & 0.1144 & 0.0776 & 0.0828 & 0.0168 & -0.0233 \\
\hline
\end{tabular}

Note: Moran's $I$ of total patent applications is measured by the k-Nearest Neighbor Weight.

Table 9. The Decay Effects of Global Spatial Dependence and Test of FDI Inflows in Chinese Provinces

\begin{tabular}{lllllllll}
\hline Year & $\mathbf{4}^{\text {th }}$-order & $\mathbf{6}^{\text {th }}$-order & $\mathbf{8}^{\text {th }}$-order & $\mathbf{1 0}^{\text {th }}$-order & $\mathbf{1 2}^{\text {h}}$-order & $\mathbf{1 6}^{\text {th}}$-order & $\mathbf{2 0}^{\text {th }}$-order & $\mathbf{2 4}^{\mathrm{h}}$-order \\
\hline 1999 & 0.0849 & 0.0652 & 0.0528 & 0.0329 & 0.0365 & 0.0219 & 0.0077 & -0.0302 \\
2000 & 0.1041 & 0.0665 & 0.0497 & 0.0359 & 0.0441 & 0.0328 & 0.0215 & -0.0276 \\
2001 & 0.1327 & 0.0872 & 0.0739 & 0.0579 & 0.0546 & 0.0486 & 0.0209 & -0.0249 \\
2002 & 0.1884 & 0.1206 & 0.0992 & 0.0855 & 0.0690 & 0.0609 & 0.0240 & -0.0243 \\
2003 & 0.3480 & 0.2289 & 0.1822 & 0.1681 & 0.0996 & 0.1019 & 0.0365 & -0.0210 \\
2004 & 0.3520 & 0.2418 & 0.2202 & 0.2026 & 0.1174 & 0.1262 & 0.0516 & -0.0148 \\
2005 & 0.3210 & 0.2087 & 0.1690 & 0.1679 & 0.0970 & 0.1042 & 0.0393 & -0.0212 \\
2006 & 0.3031 & 0.2025 & 0.1693 & 0.1635 & 0.1013 & 0.1056 & 0.0379 & -0.0355 \\
2007 & 0.2970 & 0.2069 & 0.1791 & 0.1684 & 0.1107 & 0.1042 & 0.0404 & -0.0184 \\
2008 & 0.2449 & 0.1550 & 0.1246 & 0.1041 & 0.0874 & 0.0753 & 0.0295 & -0.0215 \\
2009 & 0.2418 & 0.1532 & 0.1230 & 0.1024 & 0.0877 & 0.0749 & 0.0293 & -0.0216 \\
2010 & 0.2432 & 0.1531 & 0.1232 & 0.1023 & 0.0876 & 0.0744 & 0.0282 & -0.0215 \\
2011 & 0.2463 & 0.1548 & 0.1236 & 0.1020 & 0.0886 & 0.0752 & 0.0283 & -0.0214 \\
2012 & 0.2503 & 0.1558 & 0.1236 & 0.1011 & 0.0901 & 0.0764 & 0.0282 & -0.0212 \\
\hline
\end{tabular}

Note: Moran's I of FDI inflows is measured by the k-Nearest Neighbor Weight.

Table 10. and Table 11. report the spatial variation of innovative activities and FDI inflows across Chinese provinces over year. In accordance with the evolution of innovative activities across regions from 1999 to 2012, innovative output presents the strongly increasing trend in China over the recent years. For example, the innovative output in Beijing was 6.144 patent applications examined by per ten thousand persons in 1999, and significantly reached nearly seven times higher which was 44.607 in 2012. Respectively, the average innovative output in Zhejiang gradually reached nearly twenty-five times higher from 1999 to 2012, nearly sixty times higher in Jiangsu, eleven times higher in Shanghai, and almost fourteen times in Tianjin and so on. 
Journal of Management and Economic Studies, vol.1, issue.3, pp.43-61

Table 10. Spatial Variation of Innovative Activities based Total Patent Applications in Chinese Provinces

(units: patent applications per ten thousand persons)

\begin{tabular}{|c|c|c|c|c|c|c|c|c|c|c|}
\hline Area & 1999 & 2000 & 2005 & 2006 & 2007 & 2008 & 2009 & 2010 & 2011 & 2012 \\
\hline Beijing & 6.144 & 7.485 & 14.676 & 16.796 & 18.902 & 24.567 & 27.009 & 29.204 & 38.618 & 44.607 \\
\hline Tianjin & 2.102 & 2.786 & 11.176 & 12.371 & 14.120 & 15.502 & 15.978 & 19.990 & 28.405 & 29.020 \\
\hline Hebei & 0.503 & 0.571 & 0.934 & 1.047 & 1.131 & 1.306 & 1.615 & 1.709 & 2.430 & 3.189 \\
\hline Shanxi & 0.356 & 0.447 & 0.592 & 0.837 & 0.982 & 1.579 & 1.990 & 2.218 & 3.554 & 4.649 \\
\hline $\begin{array}{l}\text { Inner } \\
\text { Mongolia }\end{array}$ & 0.411 & 0.479 & 0.610 & 0.812 & 0.830 & 0.909 & 1.010 & 1.178 & 1.548 & 1.901 \\
\hline Liaoning & 1.454 & 1.687 & 3.713 & 3.993 & 4.541 & 4.842 & 5.944 & 7.821 & 8.465 & 9.376 \\
\hline Jilin & 0.794 & 0.917 & 1.510 & 1.681 & 1.923 & 2.025 & 2.166 & 2.347 & 2.981 & 3.334 \\
\hline Heilongjiang & 0.764 & 0.842 & 1.584 & 1.709 & 1.894 & 2.085 & 2.356 & 2.679 & 6.112 & 7.984 \\
\hline Shanghai & 3.124 & 6.772 & 18.415 & 19.858 & 22.875 & 24.682 & 28.160 & 30.919 & 34.171 & 34.734 \\
\hline Jiangsu & 0.983 & 1.104 & 4.657 & 7.055 & 11.518 & 16.491 & 22.321 & 29.974 & 44.106 & 59.679 \\
\hline zhejiang & 1.827 & 2.206 & 8.824 & 10.639 & 13.372 & 17.253 & 20.563 & 22.169 & 32.412 & 45.531 \\
\hline Anhui & 0.276 & 0.314 & 0.575 & 0.766 & 0.992 & 1.697 & 2.673 & 7.912 & 8.136 & 12.506 \\
\hline Fujian & 1.020 & 1.213 & 2.676 & 2.909 & 3.140 & 3.622 & 4.790 & 5.956 & 8.690 & 11.412 \\
\hline Jiangxi & 0.328 & 0.376 & 0.653 & 0.731 & 0.812 & 0.851 & 1.179 & 1.413 & 2.155 & 2.766 \\
\hline Shandong & 0.967 & 1.104 & 3.118 & 4.113 & 5.001 & 6.398 & 7.060 & 8.433 & 11.373 & 13.280 \\
\hline Henan & 0.368 & 0.413 & 0.957 & 1.228 & 1.594 & 2.025 & 2.065 & 2.674 & 3.630 & 4.619 \\
\hline Hubei & 0.499 & 0.578 & 2.020 & 2.560 & 3.049 & 3.703 & 4.756 & 5.466 & 7.383 & 8.880 \\
\hline Hunan & 0.521 & 0.639 & 1.385 & 1.616 & 1.768 & 2.197 & 2.490 & 3.406 & 4.475 & 5.379 \\
\hline Guangdong & 2.311 & 2.444 & 7.855 & 9.768 & 10.605 & 10.501 & 12.406 & 14.645 & 18.684 & 21.665 \\
\hline Guangxi & 0.340 & 0.393 & 0.511 & 0.590 & 0.730 & 0.806 & 0.881 & 1.110 & 1.745 & 2.907 \\
\hline Hainan & 0.490 & 0.638 & 0.601 & 0.644 & 0.748 & 1.022 & 1.204 & 1.173 & 1.697 & 2.057 \\
\hline Chongqin & 0.414 & 0.576 & 2.237 & 2.304 & 2.385 & 2.932 & 4.716 & 7.913 & 10.976 & 13.217 \\
\hline Sichuan & 0.149 & 0.540 & 1.287 & 1.605 & 2.358 & 2.990 & 4.038 & 5.001 & 6.178 & 8.211 \\
\hline Guizhou & 0.213 & 0.280 & 0.597 & 0.712 & 0.760 & 0.818 & 1.049 & 1.269 & 2.408 & 3.242 \\
\hline Yunnan & 0.297 & 0.399 & 0.574 & 0.688 & 0.689 & 0.900 & 1.014 & 1.227 & 1.544 & 1.988 \\
\hline Xizhang & 0.039 & 0.107 & 0.368 & 0.317 & 0.336 & 1.197 & 0.659 & 0.540 & 0.867 & 0.553 \\
\hline Shaanxi & 0.466 & 0.577 & 1.120 & 1.531 & 2.292 & 3.200 & 4.178 & 6.144 & 8.611 & 11.619 \\
\hline Gansu & 0.229 & 0.311 & 0.678 & 0.560 & 0.631 & 0.854 & 1.047 & 1.390 & 2.062 & 3.205 \\
\hline Qinghai & 0.337 & 0.336 & 0.398 & 0.593 & 0.701 & 0.778 & 0.895 & 1.068 & 1.288 & 1.473 \\
\hline Ningxia & 0.483 & 0.607 & 0.866 & 1.111 & 1.374 & 1.759 & 2.043 & 1.168 & 1.687 & 3.067 \\
\hline Xingjiang & 0.494 & 0.565 & 0.921 & 1.100 & 1.084 & 1.132 & 1.330 & 1.629 & 2.144 & 3.155 \\
\hline Mean & 0.926 & 1.216 & 3.100 & 3.621 & 4.295 & 5.181 & 6.116 & 7.411 & 9.953 & 12.232 \\
\hline SD & 1.200 & 1.708 & 4.469 & 5.026 & 5.880 & 6.967 & 8.020 & 9.222 & 12.252 & 14.987 \\
\hline $\mathrm{CV}$ & 0.771 & 0.712 & 0.694 & 0.720 & 0.730 & 0.744 & 0.763 & 0.804 & 0.812 & 0.816 \\
\hline
\end{tabular}

Note: it is measured by China statistical yearbooks (1999-2013); SD: standard deviation; CV: coefficient of variation.

Table 11. Spatial Variation of FDI Inflows in Chinese Provinces (units: \%)

\begin{tabular}{lllllllllll}
\hline Area & $\mathbf{1 9 9 9}$ & $\mathbf{2 0 0 0}$ & $\mathbf{2 0 0 5}$ & $\mathbf{2 0 0 6}$ & $\mathbf{2 0 0 7}$ & $\mathbf{2 0 0 8}$ & $\mathbf{2 0 0 9}$ & $\mathbf{2 0 1 0}$ & $\mathbf{2 0 1 1}$ & $\mathbf{2 0 1 2}$ \\
\hline Beijing & 4.946 & 4.174 & 4.404 & 4.082 & 4.248 & 4.346 & 4.436 & 4.593 & 4.666 & 4.756 \\
Tianjin & 4.417 & 2.891 & 4.157 & 4.017 & 4.018 & 4.148 & 4.066 & 4.224 & 3.987 & 3.786 \\
Hebei & 2.609 & 1.684 & 2.385 & 1.446 & 1.411 & 1.496 & 1.541 & 1.555 & 1.587 & 1.559 \\
Shanxi & 0.980 & 0.557 & 0.344 & 0.650 & 0.862 & 0.796 & 0.853 & 0.884 & 1.108 & 1.018 \\
Inner & & & & & & & & & & \\
Mongolia & 0.162 & 0.262 & 1.481 & 0.867 & 0.831 & 0.980 & 0.998 & 0.896 & 0.886 & 0.822 \\
Liaoning & 2.659 & 5.069 & 4.483 & 5.534 & 5.273 & 5.516 & 5.484 & 5.688 & 5.764 & 5.909 \\
Jilin & 0.754 & 0.836 & 0.825 & 1.804 & 1.519 & 0.773 & 0.802 & 0.858 & 0.808 & 0.761 \\
Heilongjiang & 0.797 & 0.746 & 1.811 & 0.802 & 0.702 & 0.715 & 0.751 & 0.756 & 0.727 & 0.708 \\
Shanghai & 7.103 & 7.835 & 8.554 & 13.206 & 12.461 & 12.999 & 12.834 & 13.078 & 13.104 & 13.175 \\
Jiangsu & 15.219 & 15.931 & 16.463 & 18.992 & 18.521 & 18.390 & 18.492 & 19.579 & 19.894 & 19.901 \\
zhejiang & 3.087 & 3.998 & 9.640 & 7.361 & 7.062 & 6.997 & 6.824 & 7.061 & 7.012 & 6.935 \\
\hline
\end{tabular}




\begin{tabular}{lllllllllll}
\hline Anhui & 0.654 & 0.790 & 0.862 & 1.072 & 1.152 & 1.126 & 1.161 & 1.168 & 1.142 & 1.272 \\
Fujian & 10.076 & 8.509 & 3.257 & 5.142 & 4.979 & 4.958 & 4.887 & 4.810 & 4.754 & 4.641 \\
Jiangxi & 0.803 & 0.563 & 3.022 & 1.359 & 1.404 & 1.481 & 1.536 & 1.692 & 1.704 & 1.715 \\
Shandong & 5.656 & 7.367 & 11.201 & 5.183 & 4.669 & 4.473 & 4.660 & 4.798 & 4.979 & 5.035 \\
Henan & 1.306 & 1.398 & 1.536 & 1.364 & 1.244 & 1.296 & 1.442 & 1.459 & 1.471 & 1.476 \\
Hubei & 2.291 & 2.340 & 2.729 & 1.640 & 1.520 & 1.505 & 1.570 & 1.652 & 1.802 & 1.856 \\
Hunan & 1.637 & 1.682 & 2.587 & 1.247 & 1.179 & 1.177 & 1.164 & 1.249 & 1.214 & 1.222 \\
Guangdong & 29.191 & 27.970 & 15.440 & 18.406 & 17.002 & 16.476 & 16.392 & 16.232 & 15.713 & 15.241 \\
Guangxi & 1.590 & 1.301 & 0.473 & 1.054 & 1.062 & 1.142 & 1.132 & 1.078 & 1.040 & 0.992 \\
Hainan & 1.213 & 1.068 & 0.854 & 0.691 & 4.562 & 4.274 & 3.759 & 0.997 & 0.766 & 0.862 \\
Chongqin & 0.598 & 0.606 & 0.644 & 0.545 & 0.959 & 1.054 & 1.157 & 1.344 & 1.569 & 1.710 \\
Sichuan & 0.854 & 1.083 & 1.107 & 1.165 & 1.303 & 1.862 & 1.919 & 2.096 & 1.994 & 2.039 \\
Guizhou & 0.102 & 0.062 & 0.134 & 0.152 & 0.136 & 0.142 & 0.148 & 0.159 & 0.197 & 0.244 \\
Yunnan & 0.385 & 0.318 & 0.217 & 0.627 & 0.574 & 0.624 & 0.661 & 0.692 & 0.717 & 0.718 \\
Xizhang & 0.000 & 0.000 & 0.014 & 0.023 & 0.025 & 0.024 & 0.026 & 0.021 & 0.025 & 0.036 \\
Shaanxi & 0.606 & 0.715 & 0.784 & 0.873 & 0.799 & 0.605 & 0.674 & 0.695 & 0.691 & 0.991 \\
Gansu & 0.103 & 0.155 & 0.025 & 0.164 & 0.149 & 0.169 & 0.205 & 0.242 & 0.222 & 0.222 \\
Qinghai & 0.011 & 0.000 & 0.332 & 0.117 & 0.118 & 0.146 & 0.118 & 0.091 & 0.109 & 0.090 \\
Ningxia & 0.129 & 0.043 & 0.176 & 0.258 & 0.106 & 0.108 & 0.105 & 0.153 & 0.153 & 0.099 \\
Xingjiang & 0.060 & 0.047 & 0.059 & 0.152 & 0.150 & 0.202 & 0.199 & 0.201 & 0.195 & 0.212 \\
Mean & 3.226 & 3.226 & 3.226 & 3.226 & 3.226 & 3.226 & 3.226 & 3.226 & 3.226 & 3.226 \\
SD & 5.862 & 5.744 & 4.425 & 4.977 & 4.703 & 4.672 & 4.646 & 4.789 & 4.780 & 4.738 \\
CV & 0.550 & 0.562 & 0.729 & 0.648 & 0.686 & 0.690 & 0.694 & 0.674 & 0.675 & 0.681 \\
\hline Note: is & & 6 &
\end{tabular}

Note: it is measured by China statistical yearbooks (1999-2013); SD: standard deviation; CV: coefficient of variation.

\section{Spatial Spillovers of FDI Inflows on Innovative Activities}

Based on the spatial dependence process described above between FDI inflows and innovative activities with respect to geographical proximity, the evidences are obtained such as the existence of a strong positive spatial dependence process, pattern of spatial clustering, as well as characteristics of spatial interdependence, heterogeneity, variation with distance increasing across Chinese provinces over year. In the following parts, by building the spatial econometrics models of knowledge spillovers and expansion of KPF framework based on contiguity, it is expected that the extent of externalities generated by innovative activities and FDI inflows based on the different spatial lagged variables are examined. Further, the paper explores the mechanisms of dissemination and agglomeration of innovative activities, which may be associated with spatial spillovers caused by FDI inflows in China.

\section{Spatial Econometric Models}

On the basis of KPF model introduced by Jaffe (1989), spatial KPF model is developed as an extension of KPF model to examine the mechanisms and determinants of interaction between FDI inflows and innovative activities as well as spatial effects of knowledge spillovers generated by FDI inflows on innovative capability. Thus, the spatial KPF model not only considers the R\&D and human capital stock in empirical model, but also introduces the variables of innovative environment such as economic developing level, employment in the manufacturing sector or high technology sector, and institutional determinants and so on, as well as the knowledge spillovers within regions and between contiguous regions. These variables include such as innovative output (patent), R\&D stock, human capital stock, FDI inflows, trade (imports \& exports), lagged variable, and agglomerative variable and so on. The expanding KPF model is formed as following:

$$
Y_{i t}=e^{\alpha_{0}} R D_{i t}^{\alpha_{1}} H_{i t}^{\alpha_{2}} F D I_{i t}^{\alpha_{3}} \operatorname{trade}_{i t}^{\alpha_{4}} Z_{i t}^{\alpha_{5}} N_{i t}^{\rho W} e^{\varepsilon_{i t}}
$$


Where $R D_{i t}^{\alpha_{1}}$ is the innovative input which includes such as R\&D expenditure, technology introducing and reconstructing; $H_{i t}^{\alpha_{2}}$ is the human capital ; $F D I_{i t}^{\alpha_{3}}$ indicates the effects of knowledge spillovers generated by FDI inflows on innovative output; $\operatorname{trad}_{i_{i t}}^{\alpha_{4}}$ indicates the imitating and demonstrating effects generated by trade flows such as exports and imports; $e^{\alpha_{0}}$ is a constant of scale; $e^{\varepsilon_{i t}}$ is a random error term which is subject to the condition of independence and the same distribution so as to capture other unobservable determinants affecting innovative output; $N_{i t}^{\rho W}$ represents the spatial lagged variable, which indicates the effects of independent and dependent variables in contiguous regions on innovative activities; $Z_{i t}^{\alpha_{5}}$ reflects the environment variables affecting innovative output in time period $t$ and region $i$, which include such variables as competitive power expressed by number of the enterprises per million persons; size of market; agglomeration economies such as density of population; infrastructure such as length or density of highway and number of mobile telephone or internet 、 economic developing level、Marshall externalities、Jacobs externalities4 and so on。 $Y_{i t}$ is a proxy for in time period $t$ and $i$ region, expressed by number of patent applications examined per ten thousands persons. Through log-transform and introducing spatial lagged variable, The KPF model can be constructed as following:

$$
\begin{array}{r}
\operatorname{Ln}\left(Y_{i t}\right)=\alpha_{0}+\alpha_{1} \operatorname{Ln}\left(R D_{i t}\right)+\alpha_{2} \operatorname{Ln}\left(H_{i t}\right)+\alpha_{3} \operatorname{Ln}\left(F D I_{i t}\right)+ \\
\alpha_{4} \operatorname{Ln}\left(\text { trade }_{i t}\right)+\alpha_{5} \operatorname{Ln}\left(Z_{i t}\right)+\rho W \operatorname{Ln}\left(N_{i t}\right)+\varepsilon_{i t}
\end{array}
$$

Where $W \operatorname{Ln}\left(N_{i t}\right)$ is the variable with spatial lagged term, which is treated as an endogenous variable to indicate spatial knowledge spillovers, and $W$ is a weight matrix; $\rho$ represents the coefficient of spatial effects of dependent or independent variables in contiguous regions. Because the OLS estimator is inconsistent and biased, the estimator based on OLS method is not longer efficient. In turn, Maximum Likelihood method corresponding with the endogenous variable $W L n\left(N_{i t}\right)$ may be applied in estimation of model.

The KPF model based on spatial error term is another method to indicate spatial process of FDI inflows and innovative activities。Spatial error model aims to identify spatial dependence in the error term. That is, each random error term in some spatial location is treated as a function of random error in the contiguous regions. Thus, KPF model with the spatial error term is constructed as following:

$$
\begin{aligned}
& \operatorname{Ln}\left(Y_{i t}\right)= \alpha_{0}+\alpha_{1} \operatorname{Ln}\left(R D_{i t}\right)+\alpha_{2} \operatorname{Ln}\left(H_{i t}\right)+ \\
& \alpha_{3} \operatorname{Ln}\left(F D I_{i t}\right)+\alpha_{4} \operatorname{Ln}\left(\text { trade }_{i t}\right)+\alpha_{5} \operatorname{Ln}\left(Z_{i t}\right)+\varepsilon_{i t} \\
& \varepsilon_{i t}=\lambda W \varepsilon_{i t}+u_{i t} \\
& u_{i t} \sim N(\mathbf{O}, \boldsymbol{u})
\end{aligned}
$$

Where $u$ is subject to asymptotically normal distribution; $\varepsilon$ follows a first-order Markov process; $\lambda$ is the spatial effects coefficient for the spatial error lag.

4Marshall externalities are also called as MAR index, and Jacobs externalities are also called as Jacobs index ( See the equation as follows). Where $E M P_{i j t}$ is the manufacturing employment aggregation in time period $t$, industry $i$, and region $j$; $Q E M_{i j t}$ is the accumulative employment aggregation of all the sectors prior to the industry $i$ sorted by employment in time period $t$ and region $j \cdot M A R_{i j t}=\left(E M P_{i j t} / \sum_{i=1}^{n} E M P_{i j t}\right) /\left(\sum_{j=1}^{m} E M P_{i j t} / \sum_{i=1}^{n} \sum_{j=1}^{m} E M P_{i j t}\right) J a c o b s s_{j t}=2 \sum_{i=1}^{n} Q E M_{i j t} /\left((n-1) \sum_{i=1}^{=n} \sum_{j=1}^{m} Q E M_{i j t}\right)$. 


\section{Model Results of Spatial Econometrics}

Table12 reports that spatial knowledge spillovers of human capital level, FDI inflows, international trade, agglomeration economies expressed by density of population, and innovative input expressed by $R \& D$ expenditures on total patent applications examined across Chinese provinces. The derived results show that human capital presents the highest coefficient which goes from 1.58 to 2.65 , and has a strongly significant value at the confidence of $1 \%$. The coefficient of international trade is next-best, and also has a strongly significant value at the confidence of $1 \%$. The coefficient of FDI inflows takes the third place, which goes from 0.252 to 0.261 , and also has a strongly significant value at the confidence of $1 \%$. The coefficient of agglomeration economies goes from 0.111 to 0.167 , and also has a significant value at the confidence of $5 \%$ and $10 \%$. The coefficient of R\&D expenditures goes from 0.038 to 0.119 , and also has a positive sign. In addition, spatial effects generated by FDI inflows, international trade, and total patent applications examined exhibit the positive effects on innovative output. by considering the effects of variables in contiguous regions, the explanatory power is increased in the models, for example, the adjusted $R^{2}$ respectively increase from 0.795 and 0.762 in traditional model 1 and model 4 to 0.796 in spatial econometric model 2 and model 5:

Table 12. Spatial Spillovers of InnovativeActivities based on the Contiguity of Innovative Output and FDI Inflows

(Based on cross section data set, observation units are 29, and dependent Variable is $\log (\mathrm{I})$ )

\begin{tabular}{|c|c|c|c|c|c|c|c|c|}
\hline $\begin{array}{l}\text { Independent } \\
\text { Variable }\end{array}$ & Model1 & Model 2 & Model 3 & $\begin{array}{l}\text { Model } 4 \\
*\end{array}$ & Model 5 * & Model 6 & Model 7 & $\begin{array}{l}\text { Model } \\
8 \\
\end{array}$ \\
\hline \multirow[t]{2}{*}{$\mathrm{C}$} & -0.595 & -0.598 & -0.621 & -0.595 & -0.589 & -0.597 & -0.794 & -0.580 \\
\hline & 0.137 & 0.089 & 0.071 & 0.137 & 0.097 & 0.100 & 0.163 & 0.081 \\
\hline \multirow[t]{2}{*}{$\log (\mathrm{h})$} & 2.149 & 2.167 & 2.151 & 2.149 & 2.130 & 2.129 & 2.138 & 1.580 \\
\hline & 0.000 & 0.000 & 0.000 & 0.000 & 0.000 & 0.000 & 0.000 & 0.000 \\
\hline \multirow[t]{2}{*}{$\log (\mathrm{FDI})$} & 0.257 & 0.259 & 0.261 & 0.257 & 0.257 & 0.265 & 0.252 & \\
\hline & 0.002 & 0.000 & 0.000 & 0.002 & 0.000 & 0.000 & 0.002 & \\
\hline \multirow[t]{2}{*}{ Log(trade) } & & & & & & & & 0.366 \\
\hline & & & & & & & & 0.000 \\
\hline \multirow[t]{2}{*}{ Log(popden) } & 0.167 & 0.171 & 0.161 & 0.167 & 0.164 & 0.164 & 0.111 & 0.072 \\
\hline & 0.076 & 0.059 & 0.046 & 0.076 & 0.046 & 0.046 & 0.444 & 0.457 \\
\hline \multirow[t]{2}{*}{$\log (R D)$} & 0.038 & 0.038 & 0.039 & 0.039 & 0.045 & 0.044 & 0.064 & 0.119 \\
\hline & 0.708 & 0.689 & 0.681 & 0.708 & 0.652 & 0.618 & 0.586 & 0.187 \\
\hline \multirow[t]{2}{*}{ WLog(I) } & & -0.025 & & & 0.013 & & & \\
\hline & & 0.891 & & & 0.864 & & & \\
\hline \multirow[t]{2}{*}{ Lambda } & & & -0.063 & & & 0.107 & & \\
\hline & & & 0.792 & & & 0.411 & & \\
\hline \multirow[t]{2}{*}{ WLog(FDI) } & & & & & & & 0.085 & \\
\hline & & & & & & & 0.611 & \\
\hline \multirow[t]{2}{*}{ WLog(trade) } & & & & & & & & 0.004 \\
\hline & & & & & & & & 0.969 \\
\hline \multicolumn{9}{|l|}{ Test of model } \\
\hline $\mathrm{R}^{2}$-adj & 0.795 & 0.796 & 0.796 & 0.762 & 0.796 & 0.804 & 0.754 & 0.861 \\
\hline $\mathrm{F}$ & 23.357 & & & 23.357 & & & 18.168 & 35.845 \\
\hline $\operatorname{Prob}(\mathrm{F})$ & 0.000 & & & 0.000 & & & 0.000 & 0.000 \\
\hline $\log (\mathrm{L})$ & -13.707 & -13.698 & 13.676 & -13.707 & -13.689 & -13.253 & -13.539 & -5.208 \\
\hline AIC & 37.413 & 39.393 & 37.352 & 37.413 & 39.378 & 36.506 & 39.078 & 22.416 \\
\hline SC & 44.250 & 47.601 & 44.188 & 44.249 & 47.582 & 43.343 & 47.282 & 30.620 \\
\hline Jarque-Bera & 2.573 & 6.804 & 6.391 & 2.573 & 6.799 & 7.478 & 2.442 & 1.183 \\
\hline
\end{tabular}




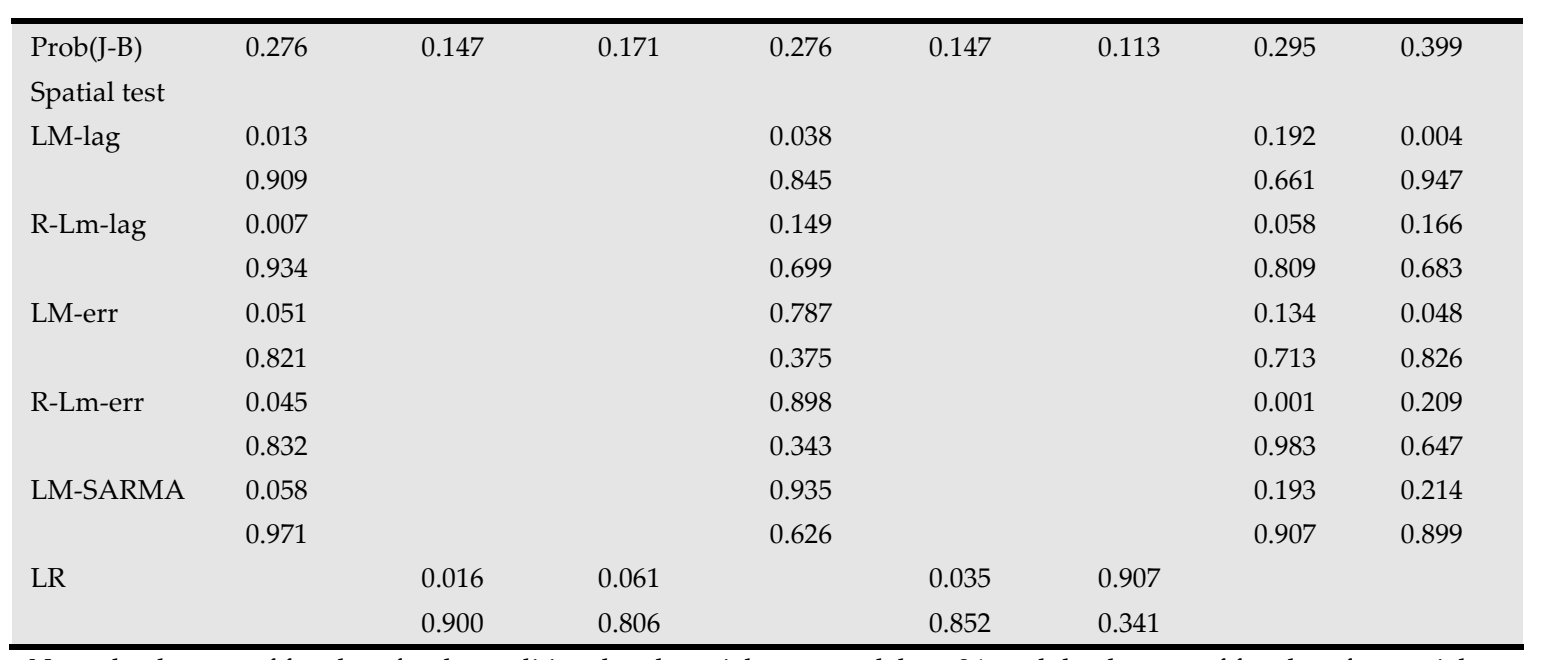

Note: the degrees of freedom for the traditional and spatial error model are 24, and the degrees of freedom for spatial lag model are 23. * indicate the spatial econometric model based on K-nearest weight matrix, and others are the spatial econometric models based on contiguous weight matrix. Besides, the test of statistical value under coefficient is P-value to show the significant of the coefficient in model.

\section{Conclusions}

The paper provides an analysis framework of spatial effects generated by FDI inflows on innovative activities, and illustrates the characteristics of spatial interdependence, heterogeneity, variation of spatial effects across Chinese provinces. The empirical evidences indicates that spatial agglomeration and proximity are the important factors affecting innovative activities and FDI inflows in spatial dimension, and also demonstrates that there exists the strongly positive spatial dependence process in innovative activities and FDI inflows across Chinese provinces.

The empirical evidences show that innovative activities and FDI inflows obey the probability distribution of NB model with the characteristics of spatial agglomeration, which implies that there are the greater potentials for further introducing FDI inflows and sustainable innovation across Chinese provinces. Secondly, spatial effects have the pattern of decreasing dependence with increasing orders, that is, knowledge spillovers present a decay process with increasing distance, which means that there exist the range of interaction and the limited spatial process in the analysis of spatial effects.

Thirdly, the innovative output not only depends on determinants within regions, but also is associated with FDI inflows and innovative activities in contiguous regions, which means that the extent of spatial clustering and contiguity plays the important role in regional innovative activities. The derived results show that the innovative output in China mainly relies on human capital, international trade, FDI inflows, agglomeration economies, as well as the spatial externalities generated by these variables.

Finally, FDI inflows in China produce the different spatial effects on all the types of innovative activities, which have the strongest knowledge spillovers effects on the patent applications examined of designs, and relatively have less knowledge effects on the patent applications examined of inventions. As a consequence, FDI inflows promote knowledge spillovers and diffusion, and also boost the knowledge exchange between Chinese and foreign enterprises so as to generate the imitating and demonstrating effects for Chinese enterprises.

In conclusion, these results demonstrate that spatial clustering and contiguity can't be ignored in the analysis of externalities of knowledge, and knowledge spillovers generated by FDI inflows are one of the main sources of sustainable innovation in China. In the aspect of policy 
implication, in order to enhance the absorbing capacity of Chinese enterprises and promote the knowledge spillovers brought by FDI inflows, it should be encouraged that policy of introducing FDI inflows not only considers quantity of FDI inflows, but also think much of quality such as FDI inflows with advance technology. Meantime, education and training as well as $R \& D$ expenditure should be widely supported so as to enhance the human capital stock in regional economic developing.

Furthermore, it should be recognized for government agency to encourage cooperation and exchange between FDI firms and universities or research organizations, and actively embed Chinese enterprises in global value chains of FDI firms so as to promote the spatial spillovers of FDI inflows on the innovative activities in China. Besides, it is helpful for decision-maker of policy to select the advantageous location to preferentially support innovative activities for increasing the extent of agglomeration economies and spatial spillovers of FDI inflows in China

\section{Acknowledgments}

Many thanks to supporting by the project of National Social Science Foundation of China, Grant No. 15BJY075.

\section{References}

Anselin, L.(2000), “Geographical and Sectoral Characteristics of Academic Knowledge Externalities", Regional Science, 70(4), 435-443.

Baltagi, B.H., Egger, P. and Pfaffermayr, M.(2007), “Estimating Models of Complex FDI: Are There Third-Country Effects?" Journal of Econometrics, 140(1), 260-81.

Berliant, Marcus, Peng, ShinKun and Wang, Ping (2002), "Production externalities and urban configuration," Journal of Economic Theory, 104(2), 275-303.

Breschi, S. and Lissoni, F.(2001), “Knowledge spillovers and Local innovation systems: A critical Survey," Industrial and Corporate Change, 10(4), 975-1005.

Coughlin, C.C., and Segev, E.(2000), “Foreign Direct Investment in China: A Spatial Econometric Study," the World Economy, 23(1), 1-23.

Fujita, Masahisa (2005), "Frontiers of the New Economic Geography," Working Paper, Institute of Economic Research, Kyoto University.

Glaeser, Edward (2001), “Cities and Skills," Journal of Labor Economics, 19, 316-342.

Glaeser, Edward L.(1999), “Learning in cities,” Journal of Urban Economics, 46(2), 254-277.

Jovanovic, Boyan and Nyarko, Yaw(1995), “ The transfer of human capital," Journal of Economic Dynamics and Control, 19(5),1033-1064.

Helsley, Robert, W.(1990), "Knowledge production in the CBD," Journal of Urban Economics, 28(3), 391-403.

Krugman, P.(1991), Geography and Trade, MIT Press, Cambridge.

Lesage, S. et al.(2007), "Knowledge Spillovers across Europe: Evidence from a Poisson Spatial Interaction Model with Spatial Effects," Regional Science, 86(3), 393-421.

Li, Xinzhong and Park, Seung Rok (2003), The Effects of Foreign Direct Investment on Economic Growth of China, Research Report, Korea Foundation for Advanced Studies (KFAS), Seoul, Korea. 
Li, Xinzhong and Wang, Tongsan(2011), The effects of spatial aggregation of FDI inflows in China on the sustaining innovation in China, research report, institute of quantitative \& technical economics, Chinese academy of social sciences, China.

Li, Xinzhong and Wang, Tongsan(2009), The Technological Spillovers Effects of FDI inflows in China, research report, Institute of Quantitative \&Technical Economics (IQTE), Chinese Academy of Social Sciences, China.

Li, Xinzhong(2005), Foreign Direct Investment Inflows in China: The Determinants at Location, in Proceedings of the International Conference, Centre National De La Recherche Scientifique (CNRS), Lyon, France.

Lucas, Robert E., Jr.(2001), “Externalities and cities," Review of Economic Dynamics, 4(2), 245-274.

Ota, Mitsuru and Fujita, Masahisa(1993,) "Communication technologies and spatial organization of multiunit firms in metropolitan areas," Regional Science and Urban Economics, 23(6), 695-729.

Park, Seung Rok andLi, Xinzhong(2006), Foreign Direct Investment and Technology Spillovers - Empirical Evidences from China, in Proceedings of The First International Symposium on Global Manufacturing and China edited by Xiaobo $\mathrm{Wu}$, Institute for Manufacturing, University of Cambridge, UK, 350-359.

Shankar, V., Milton, J. and Mannering, F.(1997,) “Modeling accident frequencies as zero-altered probability processes: An empirical inquiry," Accident Analysis and Prevention, 29(6), 829837.

Vuong, Quang H.(1989), “Likelihood ratio tests for model selection and non-nested hypotheses," Econometrica, 57(2), 307-333. 